\title{
Research on Survey on Popularizing Martial Arts in Higher Vocational Colleges and Countermeasures
}

\author{
Weina Liu \\ Wuhan International Trade University \\ Wuhan, Hubei, China
}

\begin{abstract}
At present, with the continuous development of economy and the accelerated globalization, more and more foreign sports come into China, causing great impact on traditional Chinese martial arts. As one of Chinese traditional cultures with long history, martial arts are dominated by some foreign emerging movements, which is the embarrassment of both traditional martial arts and traditional culture. Students often determine the social and cultural trend, sport is no exception. This paper analyzes developing of martial arts in college students, and gives several suggestions regarding how to publicize traditional culture and intensify the promotion of martial arts in primary and secondary schools.
\end{abstract}

Keywords-higher vocational colleges; martial art courses; traditional culture

\section{INTRODUCTION}

Martial arts are involved into the curriculum as the traditional sports and representative of excellent national culture. But in the context of new historical period and a variety of cultural conflicts, how does traditional culture work long with modern civilization? How do martial arts, the national traditional sports, coexist with various athletics? Ho How can the martial arts of college physical education adapt to the development of the times? These problems have been put in front of each martial art educator. In the process of reviewing martial arts' entering into school physical education and their history, we shall make clear development process, find out the education orientation correctly, seize the essence of martial arts and rebuild national spirit, which is the theoretical basis and logical starting point to cope with the challenges of the times and martial arts education reform. We shall involve the national spirit carrying forward and cultivation into various links and aspects of education and teaching in higher vocational colleges. In 2004, the nationality issues about education were proposed again on China's "two sessions". The formulation of these policies reflects the Party's and Government's attention and expectation toward national traditional sports. But in physical education, many problems appear in martial art course. This paper has analyzed the reasons of abovementioned and proposed some ideas for martial arts teaching in middle schools.

\section{RESEARCH OBJECT AND METHODS}

A. Research Object: Some Higher Vocational Colleges in Hubei Province

\section{B. Research Methods}

1) Case study: Make logical analysis of martial arts development in some higher vocational colleges in Hubei Province.

2) Observation: Observe the development situation of martial arts class of physical education in Wuchang University of Technology as well as students' views toward martial arts.

3) Literature: To review by entering into various literature databases.

4) Information research method: To sort and refer to the data released by the authorities.

5) Experience summary: To make a general statement about the development of martial arts in some higher vocational colleges, and give personal opinions on specific issues.

\section{RESEARCH RESULTS AND ANALYSIS}

\section{A. Survey on Development Situation of Martial Arts Class in} Some Higher Vocational Colleges in Hubei Province

Professional organization has made questionnaire survey on "Development Situation of Martial Arts Class" in higher vocational colleges in Hubei Province. The results showed that most schools do not pay attention to or just pay little attention to the class. According to the survey, some schools did not increase the content of martial arts, but reduce the content of martial arts to increase taekwondo and other foreign martial art projects.

As for the learning of martial arts or other martial art projects by students from higher vocational colleges, the participation in martial arts and other martial art projects are basically the same. But it is known that many students from higher vocational colleges do not know the difference between martial arts and other projects, and even they think generally that all martial art projects are martial arts. 


\section{B. Analysis of Development Situation of Martial Arts in Higher Vocational Colleges}

The teaching of martial arts in higher vocational colleges is not ideal. As Chinese traditional culture and sport projects, popularity of martial arts is even worse than the foreign martial art projects such as taekwondo and Muay Thai, which needs to be reflected by each coach engaged in teaching of martial arts.

1) Insufficient importance to teaching of martial arts and inadequate policy implementation: Physical Education and Health Teaching Outline implemented starting from September 1, 2001 listed martial arts as the compulsory content of physical education, playing the positive practical significance for traditional culture education for students, enriching students' extra-curricular activities and cultivation of students' lifelong physical behavior. In the process of new curriculum standard's continues reform and progress, it is required to add martial arts appropriately to physical education from the new semester. A series of policies and measures have the positive guiding significance and play the promoting role, showing the country's emphasis on traditional culture.

2) Lack of teachers and simple teaching method: First, teacher plays the leading role in teaching, and is the basic guarantee for smooth teaching. In the teaching staff of physical education in higher vocational colleges, few teachers are specialized in martial arts with basic martial arts skills. Lack of full-time teachers and the physical education teachers recruited by various schools are mostly for track and field, ball games and other specific sports. As far as I know, only a small number of physical education teachers in higher vocational colleges are specialized in martial arts while in their college years, which directly lead to the majority of physical education teachers unable to teach martial arts. Although they want to teach, they are not familiar with the contents such as exercise routines, movement demonstration as well as the explanation of attack and defense.

Furthermore, in the teaching process of martial arts in higher vocational colleges, the majority of teachers still maintain the traditional teaching mode. Teaching method is relatively simple, lack of innovation and fun, resulting in students having no passion and power in class. Over time, they are unwilling to attend to the martial arts class. Traditional teaching methods cannot present the key points and difficulties of teaching to students clearly. In addition, many of the movements are completed instantly, which has increased the difficulty in teaching. If the demonstration place cannot be selected well, students will have more difficulties in understanding and acceptance.

3) Insufficient publication of traditional culture and impact from foreign projects: As one of the excellent traditional Chinese cultures, martial arts have experienced several ups and downs through several generations, which are the combat skills and a kind of culture, containing the ancient philosophical wisdom behind the combat skills they bear. The word of "martial arts" is no stranger to the majority of students. The overwhelming martial arts film and television drama as well as the Kung fu novels of Jin Yong and Gu Long have made the words such as "martial arts" and "Kung Fu" stamped in the minds of students. "Pass without trace, fly on grass, and float on water" are the "stunt" students desire to obtain. These are students' sensible, superficial and artistic understanding toward martial arts. However, when they really start to access to martial arts and accept teachers' teaching about martial arts, the martial arts in reality is quite different from that in their imagination, as the movements of basic skills are boring, the routine is difficult to learn, hard to remember and difficult to train. Some students are laughed at by other students because their movement is not standard, thus their learning-weariness mind is generated. They tend to resist martial arts class, but prefer to play balls. If the students are forced to learn, there will be the situation of "teachers issue orders, learners cope with by force, although their bodies move, it is against their will", resulting in the embarrassing circumstances that "students like martial arts, but do not like martial arts class". The lack of publicity of such traditional culture directly results in students' deviations in understanding and losing interest in martial arts.

On the other hand, with the development of economy, more and more foreign culture come into China when the Chinese people are generating aesthetic fatigue to traditional culture, causing great impact on tradition Chinese culture. Martial arts are also difficult to escape. In recent years, South Korea's taekwondo, Muay Thai, Japanese Karate and other foreign martial art projects have emerged in Chinese traditional sports market, making domestic adolescents indifferent to martial arts gradually.

\section{Countermeasures for Popularizing Martial Arts in Higher Vocational Colleges}

1) Combine policy support and firm implementation: Some people in martial arts circles have proposed some suggestions a few years ago, for instance, open "martial arts class" separately, separating it from physical education class to form a subject parallel to physical education, thus the martial arts can be guaranteed to obtain equal importance to other subjects from class hours and teaching quality, but these suggestion are failed to be implemented. Even though these recommendations cannot be taken into consideration at present, the most basic guarantees should be able to achieve. For example, to require the teaching hours of martial arts in physical education strictly without being reduced or removed at will; intensify martial arts skills training for physical education teachers to improve teaching quality; implement martial arts rank system in higher vocational colleges, encourage and promote students' proactive learning, and encourage them to have a rank and make promotion, so that they have a goal, to motivate them to make progress.

2) Combine martial arts technology and martial arts culture: The contemporary martial arts education will become a tree without roots or the water without source if separate from martial arts culture or cultural education. In the 
inheritance of martial arts culture and connotation over thousands of years, a lot of martial arts crystallizations are summarized, such as the martial arts terminology, proverbs and verses. The process of integrating technology and culture is also a transition process of students' perceptual knowledge toward martial arts to a conceptual one, eliminating the blind worship and excessive extremeness of some students, to show them the genuine and real martial arts. Students mainly obtain their understanding to martial arts culture through film and television media. A considerable part of these works artistically exaggerate the original facts, or even tamper with history, distort the facts. They are not true martial arts. In order to learn martial arts well, we shall be diligent, free from arrogance and rashness, and learn it in a modestly and thoroughgoing manner, enabling students to realize that nothing can be done in an action in the process of their learning. And make such mentality and cognitive view extend to their future learning and life, thus to form the correct outlook on life, world outlook and cognitive concept in middle school, and play a role in the future practical activities.

3) Combine patriotism and modern fashion: Martial arts are the precious heritage of the Chinese nation handed down for thousands of years, with rich cultural heritage and mass base, having the nationality characteristic in the course of their heritage, reflecting the essence of traditional Chinese culture in particular clothing, etiquette, etc. In the era of diversification under the background of today's reform and opening up, we wonder that whether or not the new generation of students are also able to accept the traditional forms and statements with strong ethnic characteristics, such as "full discipline", "four-hit, eight-law, twelve-type", "exercise at anytime anywhere", " national treasure" and "Chinese martial arts". Therefore, the traditional national education shall be strengthened and the spirit of patriotism shall be consolidated. However, the context shall not be ignored, and too much theoretical preaching shall not be instilled into students. The nationalism and patriotism of martial arts can be reflected using idioms, classical examples, etc. We shall also pay attention to the impact by the modern fashion movement, taekwondo is an example. We shall not reject it because it is foreign, but shall involve such fashion sport into the teaching of martial arts, and find out the key of its development, popularity and spreading. Why South Korea's taekwondo, Japanese judo are able to become an official Olympic sport, yet martial arts can only be a special event at Beijing Olympic Games in 2008? Present these problems to students and make them experience and discover.

\section{CONCLUSION}

The introduction of Sports and Health Curriculum Standard in July 2001 has made a new round of reform. How will martial arts disciplines and martial arts projects adapt to the reform and development of foundation education is an important factor for martial arts' survival in school. Martial arts are the excellent national traditional sports with a strong mass base in China. Popularizing martial arts plays an extremely important role in promoting national culture, enhancing people's health and mobilizing national spirit. Today, martial arts have gradually walked out to the world, and the teaching of martial arts in domestic schools shall be implemented well really. Physical education teachers should strengthen the organization and management of teaching of martial arts, and strive to improve their teaching literacy of martial arts, and improve teaching ability comprehensively. Martial arts will have a bright future in the education in higher vocational colleges with the joint effort of education sectors sector at all levels and the physical education teachers.

\section{REFERENCES}

[1] Ministry of Education, Propaganda Department of the Central Committee of the CPC. Implementation Outline for Promoting and Cultivating National Spirit in Primary and Secondary Schools [N]. China Education Daily, 2004-04-03.

[2] Research on School Martial Arts Education Reform and Development. Sports Science. No. 29, 2009.

[3] Qiu Pixiang. Reflection Caused by "Premier Wen, Can You Play Martial Arts" [J]. Martial Arts Science, 2004.

[4] Chang Cang. Where Are the Difficulties for Martial Arts Entering into Primary and Secondary Schools [J]. Sports Culture Guide, 2003, (1): 22-23. 